\title{
Class III P-Glycoproteins Mediate the Formation of Lipoprotein X in the Mouse
}

\author{
Ronald P.J. Oude Elferink, ${ }^{\star}$ Roel Ottenhoff, ${ }^{\star}$ Jan van Marle, ${ }^{\ddagger}$ Charles M.G. Frijters, ${ }^{\star}$ Alexander J. Smith, ${ }^{\star \S}$ \\ and Albert K. Groen* \\ *Department of Gastrointestinal and Liver Diseases and ${ }^{\ddagger}$ Department of Electronmicroscopy, Academic Medical Center, ${ }^{\S}$ Section of \\ Molecular Biology, Netherlands Cancer Institute, Amsterdam, The Netherlands
}

\begin{abstract}
Cholestasis is associated with hypercholesterolemia and appearance of the abnormal lipoprotein $X(\mathrm{LpX})$ in plasma. Using mice with a disrupted Mdr2 gene, we tested the hypothesis that $\mathrm{LpX}$ originates as a biliary lipid vesicle. Mdr2deficient mice lack Mdr2 P-glycoprotein, the canalicular translocator for phosphatidylcholine, and secrete virtually no phospholipid and cholesterol in bile. Bile duct ligation of $M d r 2^{+1+}$ mice induced a dramatic increase in the plasma cholesterol and phospholipid concentration. Agarose electrophoresis, density gradient ultracentrifugation, gel permeation, and electron microscopy revealed that the majority of phospholipid and cholesterol was present as LpX, a 40-100 $\mathrm{nm}$ vesicle with an aqueous lumen. In contrast, the plasma cholesterol and phospholipid concentration in $M d r 2^{-1-}$ mice decreased upon bile duct ligation, and plasma fractionation revealed a complete absence of $L p X$. In mice with various expression levels of Mdr2 or MDR3, the human homolog of $M d r 2$, we observed that the plasma level of cholesterol and phospholipid during cholestasis correlated very closely with the expression level of these canalicular P-glycoproteins. These data demonstrate that during cholestasis there is a quantitative shift of lipid secretion from bile to the plasma compartment in the form of $\mathrm{LpX}$. The concentration of this lipoprotein is determined by the activity of the canalicular phospholipid translocator. (J. Clin. Invest. 1998. 102:17491757.) Key words: cholestasis • hypercholesterolemia • P-glycoprotein $\bullet$ multidrug resistance $\bullet$ bile $\bullet$ lipoproteins
\end{abstract}

\section{Introduction}

It is well known that plasma cholesterol levels increase during obstructive jaundice. This hypercholesterolemia is mainly due to unesterified cholesterol and is accompanied by the appearance of an abnormal lipoprotein, lipoprotein $\mathrm{X}(\mathrm{LpX})^{1}(1)$. Several decades ago, the aberrant mobility of plasma lipopro-

Address correspondence to Ronald Oude Elferink, Ph.D., Department of Gastrointestinal and Liver Diseases, Academic Medical Center F0-116, Meibergdreef 9, 1105 AZ Amsterdam, The Netherlands. Phone: 31-20-566-3828; FAX: 31-20-566-9190; E-mail: r.p. oude-elferink@amc.uva.nl

Received for publication 1 April 1998 and accepted in revised form 8 September 1998.

1. Abbreviations used in this paper: BDL, bile duct ligation; FPLC, fast performance liquid chromatography; LpX, lipoprotein X; PC, phosphatidylcholine; Pgp, P-glycoprotein.

J. Clin. Invest.

(C) The American Society for Clinical Investigation, Inc. 0021-9738/98/11/1749/09 \$2.00

Volume 102, Number 9, November 1998, 1749-1757

http://www.jci.org teins from cholestatic patients was already demonstrated via agarose electrophoresis (2) and gradient ultracentrifugation (3). Upon agarose electrophoresis, human LpX migrates toward the anode more slowly than all normal lipoproteins, and on agar electrophoresis it may even migrate toward the cathode $(4,5)$. Upon gradient ultracentrifugation, $\mathrm{LpX}$ sediments in the LDL fraction (3). LpX from cholestatic humans and rats appears to have very similar characteristics (3). Using smallangle X-ray scattering, it was shown that $\mathrm{LpX}$, in contrast to the normal serum lipoproteins, is a unilamellar vesicle with an aqueous lumen $(6,7)$. It was postulated that LpX particles represent biliary vesicles, which are regurgitated into the plasma of cholestatic subjects (5). This hypothesis is plausible because LpX particles and biliary lipid vesicles are both lipsomes which almost exclusively contain phosphatidylcholine and free cholesterol (8). In contrast to biliary vesicles, however, LpX contains some apolipoprotein (apoC) as well as albumin (9). Furthermore, in rats, the cholesterol/phospholipid ratio of $\mathrm{LpX}$ (about 1:1) is different from this ratio in bile (about 1:10). These changes could be brought about by interactions of $\mathrm{LpX}$ with other lipoproteins in the plasma. Note, however, that LpX may also appear under conditions that are not associated with overt cholestasis. Thus, $\mathrm{LpX}$ is observed in the plasma of patients with a deficiency of lecithin/cholesterol acyltransferase (10) and during intravenous infusion of phospholipid (11). The question therefore remains how $\mathrm{LpX}$ is generated.

We have recently demonstrated that biliary phospholipid secretion is virtually completely abrogated in mice with a disrupted Mdr2 gene (12). The product of this gene, Mdr2 P-glycoprotein (Pgp), is localized in the canalicular membrane of the hepatocyte and translocates phosphatidylcholine (PC) from the inner to the outer leaflet of the membrane, thereby making it available for bile salt-induced secretion into the canalicular lumen (for review see reference 13). Although the precise mechanism of this complex secretory process is still unknown, we (14) and others (15) have hypothesized that the ATP-driven translocation of PC by Mdr2 Pgp causes a surplus of PC in the outer leaflet. In combination with the bile saltinduced destabilization of the outer leaflet lipids, this leads to the formation of phospholipid vesicles that subsequently pinch off from the outer leaflet. This mechanism is speculative but supported by data from Crawford et al. (15), who observed the presence of membrane-adherent vesicles in canaliculi of ultrarapid-frozen liver specimens. The presence of these adherent vesicles was strictly dependent on bile salt secretion and was strongly decreased in $M d r 2^{-l-}$ mice (16). These data suggest, but do not prove, that formation of vesicles is the primary event in Mdr2 Pgp-mediated phospholipid secretion. Clearly, additional data are required to validate this theory. The $M d r 2^{-1-}$ mouse is the animal model of choice to test the hypothesis that $\mathrm{LpX}$ originates as a biliary vesicle. We therefore induced extrahepatic cholestasis in both normal and $M d r 2^{-/-}$ mice by bile duct ligation (BDL) and analyzed the serum lipoprotein composition in these mouse strains. Using a combina- 
tion of gradient ultracentrifugation and gel chromatography, we purified the LpX fraction and demonstrated by electron microscopy that it is a bilayer vesicle. Furthermore, we observed that this LpX particle is completely absent in $M d r 2^{-1-}$ mice and that its level in the plasma during extrahepatic cholestasis is entirely determined by the expression level of class III Pgp's, i.e., Mdr2 Pgp or MDR3 Pgp, which is the human homolog of Mdr2.

\section{Methods}

Animals. The generation of the different transgenic mouse strains has been reported elsewhere (17). All animals were bred against the same FVB genetic background, and for all experiments we used female mice. The animals were fed ad libitum with lab chow and had free access to water. For BDL, the animals were anesthetized by intraperitoneal injection of $1 \mathrm{ml} / \mathrm{kg}$ Hypnorm (fentanyl/fluanisone) and $10 \mathrm{mg} / \mathrm{kg}$ diazepam. The abdomen was opened by midline incision. The common bile duct was ligated as close to the liver as possible, and the gallbladder was ligated and removed. Subsequently, the abdomen was closed again. Sham operation included midline incision, manipulation of the intestines and bile duct, and closure of the abdomen. After the indicated period of cholestasis, the animals were anesthetized again, EDTA blood was obtained by puncture of the heart, and this was immediately centrifuged to obtain plasma. The liver was excised and a homogenate was prepared, which was subjected to Folch extraction. The organic solvent phase was evaporated and the extract redissolved in isopropanol. Subsequently, free and esterified cholesterol were determined in the extract.

To determine the maximal biliary phospholipid secretion capacity, the gallbladder of the mice was cannulated after distal ligation of the common bile duct. Bile was diverted for $90 \mathrm{~min}$ to deplete the endogenous bile salt pool. Subsequently, tauroursodeoxycholate (dissolved in PBS) was infused into the tail vein at stepwise increasing rates from $600-2400 \mathrm{nmol} / \mathrm{min} 100 \mathrm{~g}$. Bile was collected in $10 \mathrm{~min}$ fractions and analyzed for phospholipid content.

Anaytical procedures. Agarose electrophoresis was performed as follows. Sudan Black ( $0.2 \% \mathrm{wt} / \mathrm{vol}$ final concentration) was added to EDTA plasma samples, and the mixture was incubated for $15 \mathrm{~min}$ at $45^{\circ} \mathrm{C}$. Subsequently, an equal volume of $0.5 \%$ agarose was added at $45^{\circ} \mathrm{C}$, and the sample was applied to a $0.5 \% \mathrm{wt} / \mathrm{vol}$ agarose gel containing $100 \mathrm{mM}$ Tris- $\mathrm{HCl}, \mathrm{pH}$ 8.2. The gel was immersed in $50 \mathrm{mM}$ barbital/ $\mathrm{HCl}, \mathrm{pH} 8.8$, and electrophoresis was performed at $150 \mathrm{~mA}$ for $3 \mathrm{~h}$, and the resulting banding pattern was photographed.

Density ultracentrifugation in $\mathrm{KBr}$ gradients was performed as described by Chapman et al. (18). After centrifugation (48 h at $100,000 \mathrm{~g}$ ), 1-ml fractions were collected from the gradient in which density and lipid content were measured.

Fast performance liquid chromatography (FPLC) of ultracentrifuge gradient fractions was performed on a Superose $6 \mathrm{~B}$ column (Pharmacia, Uppsala, Sweden). A 200- $\mu$ l fraction was applied to a 25$\mathrm{ml}$ Superose 6B (HR10/30) column, which was equilibrated and run in PBS with a flow rate of $0.5 \mathrm{ml} / \mathrm{min}$. 500- $\mu$ l fractions were collected and assayed for phospholipid and cholesterol. The column was calibrated with normal human plasma samples.

Immunofluorescence microscopy. Excised livers, immediately frozen in liquid nitrogen, were cryosectioned, and the 5- $\mu \mathrm{m}$ sections were fixed with acetone. Subsequently, the sections were blocked by incubation in $4 \% \mathrm{vol} / \mathrm{vol}$ normal goat serum in PBS and incubated for $1 \mathrm{~h}$ with 1:10 diluted rabbit anti-REG3 in PBS. After washing, the slides were incubated with FITC-conjugated goat anti-rabbit in PBS containing $4 \% \mathrm{vol} / \mathrm{vol}$ normal mouse serum for $1 \mathrm{~h}$, washed, and analyzed by confocal laser scanning microscopy.

Electron microscopy. For negative staining, the fractions were adsorbed to formvar-coated 400-mesh grids and stained with uranyl acetate $(1 \%)$. Samples for freeze fracture were vitrified in liquid ethane and fractured in a BAF300 (Balzers, Liechtenstein) at $150 \mathrm{~K}$ and a vacuum $<10^{-5} \mathrm{~Pa}$, replicated at $45^{\circ}$ with $2 \mathrm{~nm} \mathrm{Pt}$, and strengthened with $20 \mathrm{~nm} \mathrm{C}$. The replicas were cleansed with commercial household bleach, rinsed with distilled water, and collected on bare 300-mesh grids.

For cryoelectron microscopy, 400-mesh grids were dipped into the samples, blotted with filter paper, and vitrified in liquid ethane kept at liquid nitrogen temperature with a gravity-driven guillotine device. Samples were studied and photographed with an EM420 electron microscope (Philips, Eindhoven, The Netherlands) operated at $100 \mathrm{kV}$ at magnifications of $\times 15,000$ and $\times 18,000$.

Assays. Bilirubin was determined by routine clinical chemical measurement; the lower detection limit was $2 \mu \mathrm{M}$. Free cholesterol was measured by an enzymatic assay, using the cholesterol oxidase reaction coupled to fluorimetric determination of hydrogen peroxide. This was a modification of the procedure described by Huang et al. (19). In brief, the hydrogen peroxide generated by cholesterol oxidase is used to oxidize the nonfluorescent homovanillic acid to the fluorescent dimer. The assay mixture contained $1 \mathrm{mM}$ homovanillic acid (Merck, Darmstadt, Germany), $100 \mathrm{mU} / \mathrm{ml}$ horseradish peroxidase (Boehringer, Mannheim, Germany), $0.15 \mathrm{mU} / \mathrm{ml}$ cholesterol oxidase (Boehringer), and $0.05 \%$ vol/vol Triton X-100 in $50 \mathrm{mM}$ Mops, $\mathrm{pH}$ 7.7. The change in fluorescence was measured at $425 \mathrm{~nm}$ (excitation $327 \mathrm{~nm}$ ). Total cholesterol was measured after the addition of cholesterol esterase $(0.4 \mathrm{U} / \mathrm{ml}$; Boehringer $)$. The difference between free and total cholesterol was taken as the amount of esterified cholesterol. Phospholipid levels were determined by a similar approach using the oxidation of choline to generate hydrogen peroxide. The choline was liberated by treatment with phospholipase D. The medium for this assay contained $1 \mathrm{mM}$ homovanillic acid, $0.1 \mathrm{U} / \mathrm{ml}$ choline oxidase (Boehringer), $0.2 \mathrm{U} / \mathrm{ml}$ phospholipase $\mathrm{D}, 40 \mathrm{mU} / \mathrm{ml}$ horseradish peroxidase, $10 \mathrm{mM} \mathrm{CaCl}_{2}, 0.05 \%$ vol/vol Triton X-100, and $50 \mathrm{mM}$ Mops, pH 8.0. Triglycerides were measured after hydrolysis with lipase and subsequent determination of glycerol with glycerol kinase and glycerol phosphate oxidase (GPO-PAP kit; Boehringer).

\section{Results}

Hypercholesterolemia in bile duct-ligated mice. To study the formation of $\mathrm{LpX}$ in mice during cholestasis, both control $\left(M d r 2^{+/+}\right)$and $M d r 2^{-/-}$mice were subjected to BDL, and after different time periods plasma was collected. Bilirubin levels rose rapidly within $1 \mathrm{~d}$ to $200 \mu \mathrm{M}$, and subsequently slowly increased further to $300 \mu \mathrm{M}$ during the following $14 \mathrm{~d}$. The rise in serum bilirubin was similar in $M d r 2^{+/+}$and $M d r 2^{-/-}$mice (not shown). Fig. $1 a$ shows that the total cholesterol level in plasma of $M d r 2^{+/+}$mice started to rise after a lag period of $8 \mathrm{~h}$. The plasma phospholipid levels closely followed that of cholesterol. After $48 \mathrm{~h}$, the plasma cholesterol as well as the phospholipid concentrations were at a maximum, after which they slightly decreased and reached a constant level for at least $14 \mathrm{~d}$ of BDL. In sham-operated $M d r 2^{-1-}$ mice, the plasma cholesterol and phospholipid levels were significantly lower than in controls $(40 \pm 9 \%)$, as has been described before by Voshol et al. (20). In contrast to the $M d r 2^{+/+}$mice, BDL in $M d r 2^{-/-}$mice did not induce a rise in plasma phospholipid or cholesterol but resulted in a significant further decrease (Fig. 1a). It is known that in rats and humans, the rise in plasma cholesterol during cholestasis represents mainly free cholesterol. We, therefore, determined the percentage of free versus esterified cholesterol during the different time periods of cholestasis. Fig. $1 b$ shows that in sham-operated $M d r 2^{+/+}$mice, $15 \pm 5 \%$ of the plasma cholesterol is in the unesterified form. BDL induced a significant increase in the fraction of free cholesterol already after the shortest sampling point ( $4 \mathrm{~h} ; 48 \pm 4 \%$ ); the fraction of free cholesterol further rose to $90 \pm 12 \%$ and remained constant at 

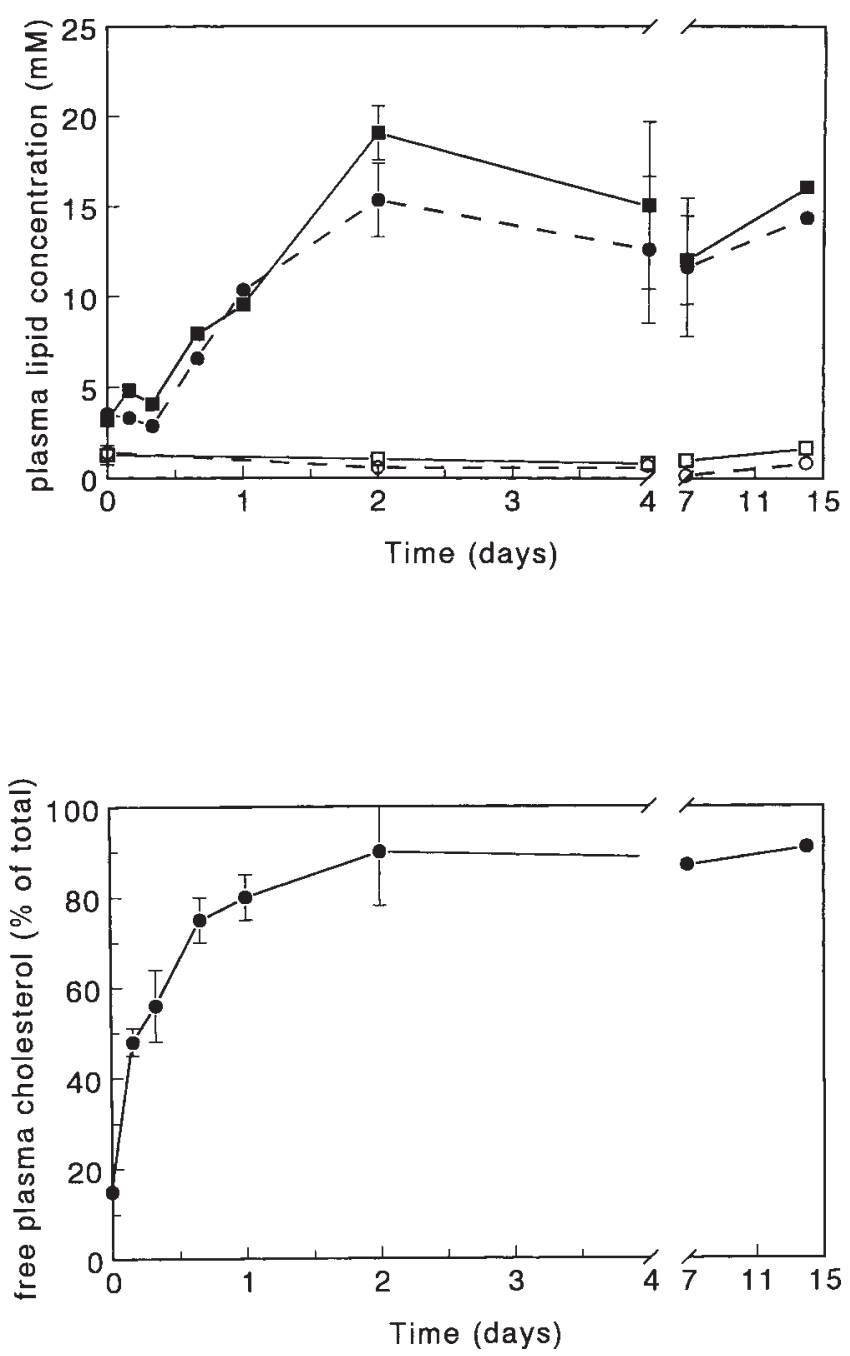

Figure 1. Plasma cholesterol and phospholipid levels during BDL. $M d r 2^{+/+}$and $M d r 2^{-/-}$mice were subjected to BDL, and after the indicated time periods, plasma was sampled and the concentrations of phospholipids and total cholesterol were determined. The values represent means \pm SD from three or more animals. (Upper panel) Total cholesterol and phospholipid in plasma. Closed symbols, Mdr2 $2^{+/+}$ mice; open symbols, $M d r 2^{-l-}$ mice; circles, total cholesterol; squares, phospholipid. (Lower panel) Percentage of free cholesterol of total cholesterol in $M d r 2^{+/+}$mice after BDL.

this level. The change in the fraction of free cholesterol was much faster than the change in total cholesterol concentrations in plasma, which lagged during the first $8 \mathrm{~h}$ of BDL (Fig. $1 \mathrm{a}$ ). Sham-operated $M d r 2^{-1-}$ mice had the same fraction of free cholesterol in their plasma as sham-operated controls. Due to the strong decrease in cholesterol levels during BDL, the percentage of free versus esterified cholesterol could not be determined accurately in $M d r 2^{-1-}$ mice.

The presence of $L p X$ in plasma of bile duct-ligated mice. To assess whether $\mathrm{LpX}$ was generated in BDL mice, plasma samples from sham-operated as well as bile duct-ligated $M d r 2^{+/+}$and $M d r 2^{-1-}$ mice were subjected to agarose gel electrophoresis. Plasma from sham-operated $M d r 2^{+/+}$mice (Fig. 2, lane 2) displayed two bands; the main band with high mobility represents HDL. The minor band with lower mobility probably represents VLDL. In plasma from sham-operated $M d r 2^{-1-}$

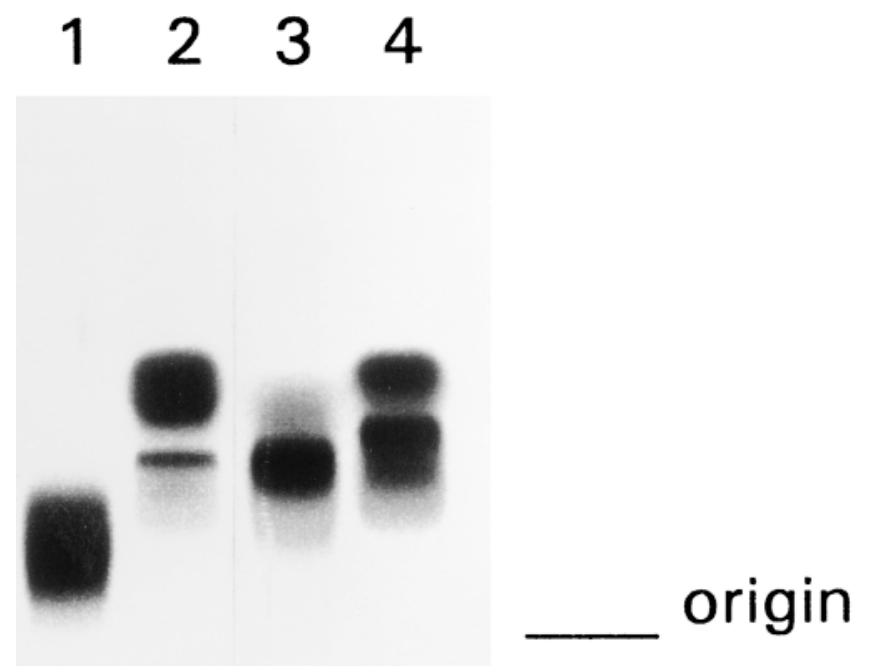

Figure 2. Agarose gel electrophoresis of plasma samples from $M d r 2^{-1-}$ and $M d r 2^{+/+}$mice during BDL. $M d r 2^{+/+}$and $M d r 2^{-/-}$mice were subjected to BDL for $4 \mathrm{~d}$, after which plasma was sampled and electrophoresed on agarose as described in Methods. A tenfold higher amount of plasma from the $M d r 2^{-1-}$ mice was applied to the gel compared with the samples from $M d r 2^{+/+}$animals because of the lower plasma lipid content (see Fig. 1, upper panel). (Lane 1) BDL $M d r 2^{+/+}$; (lane 2) sham-operated $M d r 2^{+/+}$; (lane 3) BDL $M d r 2^{-/-}$; (lane 4): sham-operated $M d r 2^{-1-}$.

mice, relatively less lipid migrated with the HDL fraction (Fig. 2, lane 4). In plasma samples from bile duct-ligated $M d r 2^{+/+}$ mice, all lipids had shifted toward a single band with very low mobility (Fig. 2, lane 1). Although lipids in plasma samples from bile duct-ligated $M d r 2^{-/-}$mice did shift slightly toward a lower mobility, the change was by far not as dramatic as in $M d r 2^{+/+}$mice (Fig. 2, lane 3). It should be noted that equal amounts of lipid were applied to the gel, i.e., more plasma from the $M d r 2^{-1-}$ mice than from $M d r 2^{+/+}$mice because the latter contains more lipid (see Fig. $1 a$ ).

To separate and analyze the different lipoproteins, we fractionated plasma by $\mathrm{KBr}$ gradient ultracentrifugation. In all fractions, triglycerides, phospholipid, total cholesterol, and free cholesterol were measured. Fractionation of $M d r 2^{+/+}$ mouse plasma (Fig. 3) revealed that the majority of the plasma lipids $(71 \%)$ in sham-operated animals was present in the HDL fraction (fractions 8 and 9; density 1.05-1.10 g/ml). A relatively small amount of lipid (about $12 \%$ ) was present in the LDL fraction (fractions 5-7; density 1.03-1.05 g/ml), in line with what is generally observed in rodents. The majority of triglycerides was present in the VLDL fraction (fractions 1 and 2; density $<1.02 \mathrm{~g} / \mathrm{ml}$ ). After $4 \mathrm{~d}$ of BDL in $M d r 2^{+/+}$, a major shift in the lipid distribution over the lipoprotein fractions was observed (Fig. 3, lower panel). The lipid content of the HDL fraction was reduced, and this was accompanied by a massive increase in the LDL fraction. Because it is known that $\mathrm{LpX}$ sediments in the LDL fraction in $\mathrm{KBr}$ gradients $(3,21)$, we further fractionated the LDL fraction by gel permeation on FPLC (Fig. 4). The FPLC column (Superose 6B; Pharmacia) was calibrated with human plasma, the lipoproteins of which elute at the same position as rodent lipoproteins (see also Voshol et al. (20)). The position at which VLDL, LDL, and HDL elute is indicated in Fig. 4. On the basis of its large size, $\mathrm{LpX}$ is expected to elute in the void volume (VLDL fraction) 

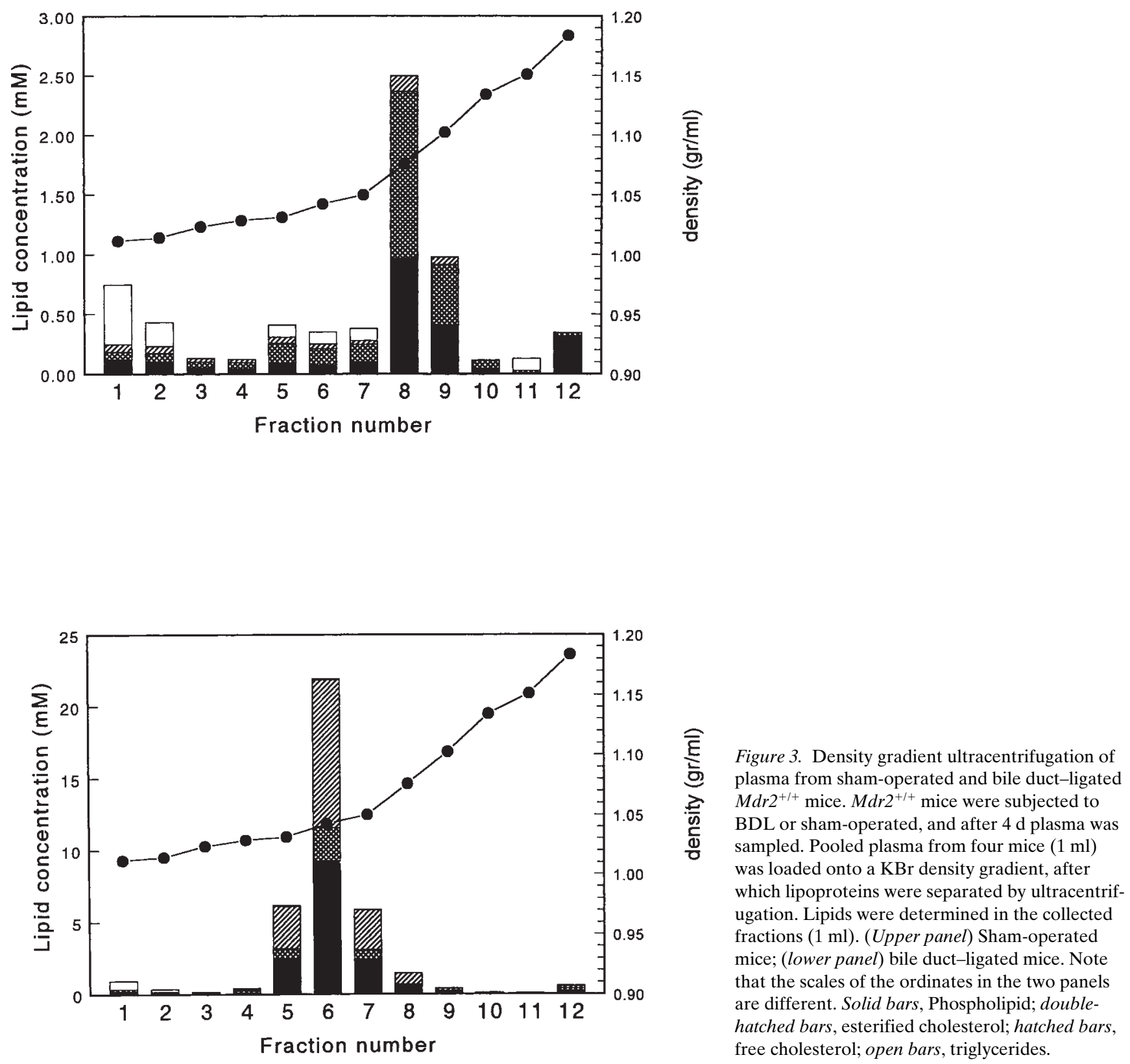

(4). When the LDL fraction from the ultracentrifuge gradient of bile duct-ligated $M d r 2^{+/+}$mice was applied to the FPLC column, the majority of phospholipid (Fig. 4), as well as cholesterol (not shown), eluted in the void volume of the column, indicating that it represents a particle that is too big for normal LDL and probably represents LpX. As a control, the HDL fraction from sham-operated $M d r 2^{+/+}$mice was also applied to the column, and this eluted in the expected region. The LDL fraction from BDL mice contained too little lipid to be detected after gel permeation.

To ascertain the presence of LpX in the LDL fraction electron microscopically, we used negative staining, freeze fracture, and cryoelectron micrscopy. Negative-stained samples revealed typical liposomal structures ranging from 40-100 nm, which are characteristic of LpX (Fig. $5 a$ ), in the LDL fraction of bile duct-ligated $\mathrm{Mdr}^{+/+}$mice. Other structures, solid discs (15-30 nm), were observed occasionally; they were identified as lipoprotein particles. Freeze fracture (Fig. $5 c$ ) and cryoelec- tron microscopy (Fig. $5 d$ ) unequivocally demonstrated the membrane-bound structure of the heterogenous population of vesicles present in the LDL fraction. Some vesicles in this fraction were oligolamellar, a feature difficult to observe in negative-stained specimens. The conclusion from the biochemical and electronmicroscopic data presented above must be that the majority of the lipid in the plasma of bile duct-ligated $M d r^{+/+}$mice is present as LpX.

The absence of $\mathrm{LPX}$ in plasma of bile duct-ligated $M d r 2^{-/-}$ mice. We subsequently also subjected plasma from $M d r 2^{-1-}$ mice to the same procedures. Density gradient ultracentrifugation shows that the reduction in plasma lipids in sham-operated $M d r 2^{-1-}$ mice compared with control mice predominantly involves a reduced HDL content (Fig. 6, upper panel; see also Voshol et al. (20)). BDL led to a reduction in the HDL fraction (Fig. 6, lower panel) as it did in $M d r 2^{+/+}$. In contrast, however, the lipid content in the LDL fraction of bile duct-ligated $M d r 2^{-1-}$ did not increase but decreased. The HDL in the 


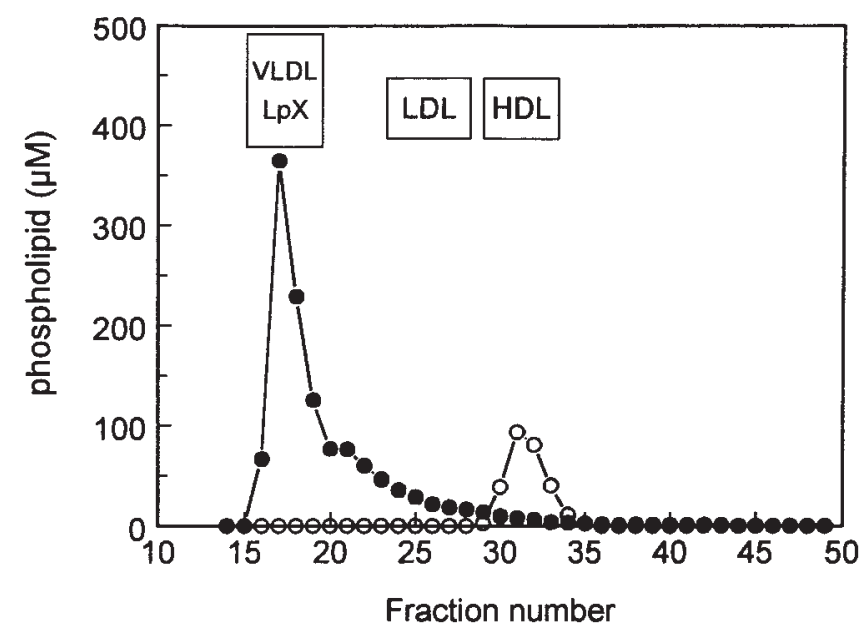

Figure 4. Gel permeation of the major lipoprotein fractions from sham-operated and bile duct-ligated $\mathrm{Mdr}^{+/+}$mice. From the peak fractions of the gradients described in Fig. 3, 200- $\mu$ l samples were applied to an FPLC gel filtration column which was run with PBS as eluent. The fractions $(0.5 \mathrm{ml})$ of the eluate were assayed for phospholipid. The column was calibrated with human control plasma samples, which have the same retention times as rodent lipoproteins. Closed circles, LDL fraction from a bile duct-ligated $\mathrm{Mdr} 2^{+/+}$mice, open circles, HDL fraction from sham-operated $M d r 2^{+/+}$mice.

plasma of bile duct-ligated $M d r 2^{-/-}$mice appeared to sediment at a somewhat higher density than in sham-operated $M d r 2^{-1-}$ mice or control mice. The free cholesterol content did not increase in any of the fractions. This indicated that essentially no LpX was formed in bile duct-ligated $M d r 2^{-1-}$ mice. To further substantiate this, we investigated the LDL fraction from these mice electron microscopically with negative staining (Fig. 5 b). A 100-fold more concentrated fraction was used compared with the equivalent fraction from bile duct-ligated $M d r 2^{+/+}$mice, because of the much lower lipid content. Only occasionally a liposomal strucure was observed, while the majority of particles was a mixture of mainly small (HDL) or very large irregular membranous structures.

Relation between Mdr2 or MDR3 Pgp expression and the $L p X$ concentration in plasma. It was subsequently tested whether the accumulation of cholesterol and phospholipid in the plasma of BDL mice is related to the expression level of phospholipid-translocating Pgp's (class III, i.e., the murine Mdr2 and the human MDR3 Pgp $(13,22)$ ). This was important, to exclude the possibility that the absence of $\mathrm{LpX}$ is related to the observed liver disease in the $M d r 2^{-1-}$ mice (12). A set of different animals was used to test this question. Apart from the $M d r 2^{+/+}$mouse (100\% Mdr2 Pgp), the $M d r 2^{+/-}$mouse $(50 \%$ Mdr2 Pgp), and the $M d r 2^{-/-}$mouse (0\% Mdr2 Pgp), we also used two strains of mice (A63 and A1) that bear a transgene for the human homolog, $M D R 3$. These animals express MDR3 Pgp only in the liver, because the transgenic construct contained an albumin promotor (17). The A63 $\left(\mathrm{MDR}^{+/+} \mathrm{Mdr2^{+/+ }}\right)$ mouse is a transgenic animal that expresses MDR3 Pgp in addition to Mdr2 Pgp at a level of about 200\% of the Mdr2 Pgp in controls. This strain will be further referred to as A63. The A1 $\left(M_{D R} 3^{+/+} M d r 2^{-/-}\right)$is a rescue strain that has no expression of Mdr2 Pgp and expresses MDR3 Pgp at about $8 \%$ of the control level (17). This strain will be further referred to as A1.

We determined the maximal phospholipid secretion capacity in all these animals by stepwise increased intravenous infu- sion of tauroursodeoxycholate during bile canulation. Fig. 7 shows that the biliary phospholipid secretion capacity closely correlated with the expression level of either Mdr2 or MDR3 Pgp; bile salt-dependent phospholipid secretion was $200 \%$ of control in the A63 strain and 8\% of control in the A1 strain. Thus, a set of animals was available with a wide variation (0 $200 \%$ of control) in biliary phospholipid secretion. Animals from all these strains were subjected to BDL for $4 \mathrm{~d}$. Subsequently, plasma was collected and analyzed for phospholipid, total cholesterol, and triglyceride (Fig. 8). Both phospholipid and cholesterol accumulated in plasma of bile duct-ligated animals to an extent that closely correlated with the expression of Mdr2 or MDR3 Pgp. Note that in sham-operated animals there was no consistent difference in plasma lipid levels between the various strains, except for the $M d r 2^{-1-}$ and the A1 strain, which have reduced levels of both phospholipid and cholesterol. The triglyceride content of the plasma varied considerably, but there was no correlation with the expression level of class III Pgp's. In addition, there was no consistent difference between the triglyceride levels in sham-operated and bile duct-ligated animals.

It is clear that the plasma phospholipid and cholesterol levels become exceedingly high in the A63 mice with high MDR3 Pgp expression. To check whether in this abnormal situation the lipoprotein distribution is similar to that in normal mice, we subjected the plasma of both sham-operated and bile ductligated A63 mice to gradient ultracentrifugation (not shown). The distribution of phospholipid and cholesterol over the fractions was identical to that in $M d r 2^{+/+}$mice; in sham-operated animals, the majority of phospholipid and cholesterol was present in the HDL fraction, while BDL led to a decrease in the HDL fraction and an increase in the LDL fraction.

We tested whether the production of different amounts of $\mathrm{LpX}$ in the various mouse strains had any consequences for the liver content of cholesterol. To this end, liver homogenates of sham-operated and BDL mice of all strains (except A1) were prepared, lipids were extracted, and the content of free and esterified cholesterol was determined. The hepatic cholesterol content of $M d r 2^{+/+}$mice was $28.4 \pm 4.7 \mu \mathrm{mol} / \mathrm{g}$ of dry weight and this did not change after BDL. The hepatic cholesterol of the other mouse strains did not significantly deviate from $M d r 2^{+/+}$mice, neither after sham operation nor after BDL. There was also no difference in the percentage of free cholesterol in the liver $(16 \pm 5 \%)$.

Localization of Mdr2 Pgp during BDL. Our data indicate that during BDL there is a quantitative shift of biliary lipid secretion to the plasma compartment and that this is critically dependent on the activity of Mdr2 or MDR3 Pgp. The question therefore arises of where Pgp is present during BDL. To investigate this, we stained liver sections from sham-operated and bile duct-ligated $\mathrm{Mdr} 2^{+/+}$mice with $\mathrm{mAb}$ anti-REG3. This antibody specifically reacts with Mdr2 Pgp and not with other Pgp's (23).

Immunofluorescence of these sections (Fig. 9) demonstrates that both in sham-operated and in bile duct-igated liver the protein is exclusively present in the canalicular region and not in the basolateral membrane. This was further confirmed by double staining with an antibody for ZO-1, which colocalizes in the canalicular region (not shown). In sham-operated animals, a defined staining pattern of the canalicular membrane was observed (Fig. $9 a$ ). Liver sections of bile ductligated animals revealed a fuzzy, vesicular pattern in and around 

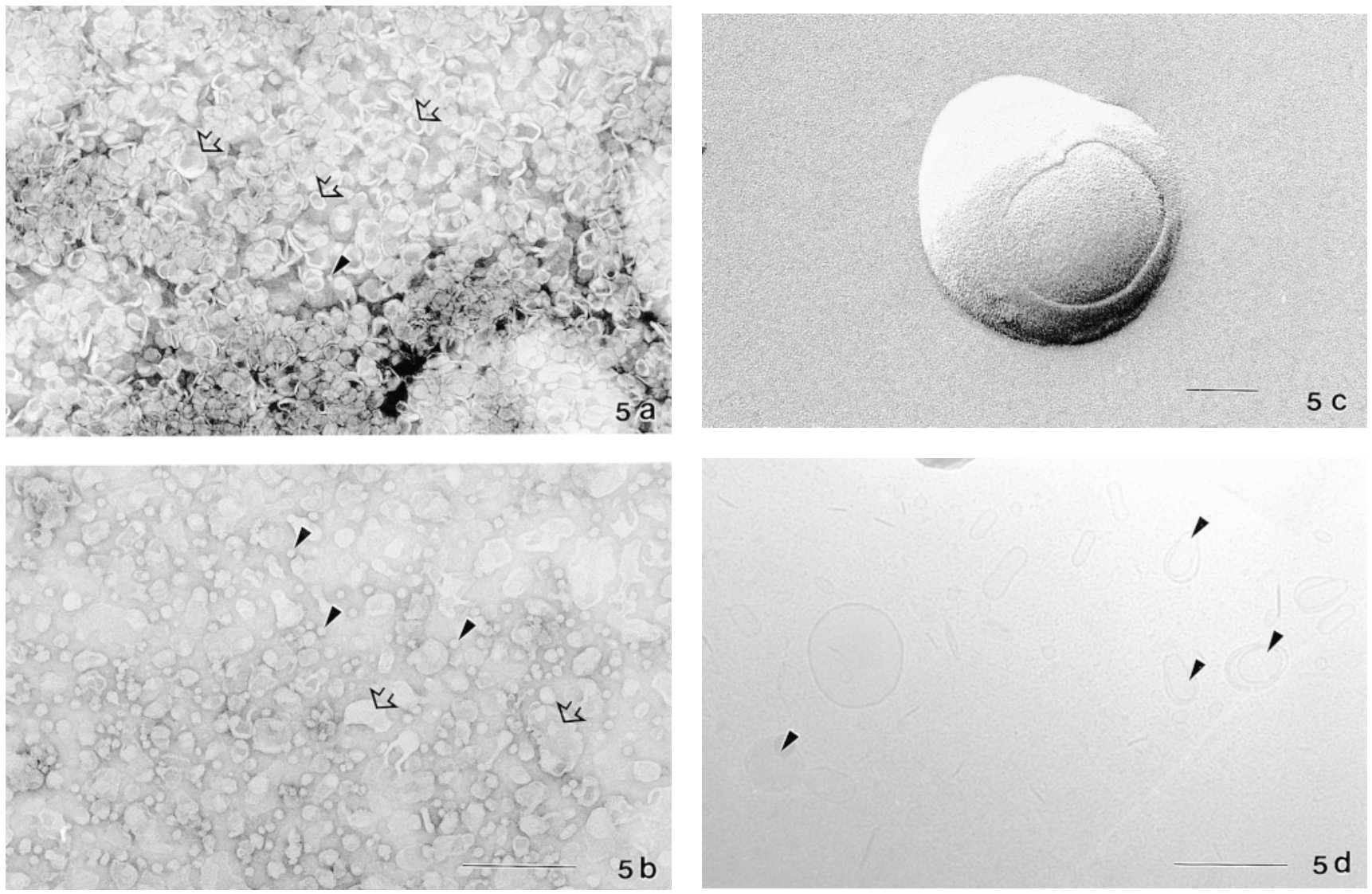

Figure 5. Electron microscopy of the LDL fraction from bile duct-ligated $M d r 2^{+/+}$and $M d r 2^{-/-}$mice. (a) Negative staining of a sample from the LDL fraction of bile duct-ligated $M d r 2^{+/+}$mice (see Fig. 3). The lipid particles in this fraction are mainly characteristic liposomal structures (open arrows). Occasionally, small LDL particles are encountered (arrowhead). (b) Negative staining of a sample from the LDL fraction of bile duct-ligated $M d r 2^{-1-}$ mice. This fraction was 100-fold more concentrated than the sample from $(a)$, because of the much lower lipid content of this fraction (compare Figs. 3 and 6, lower panels). It contains irregular membranous structures of unknown origin (open arrows) while the majority represent small LDL particles (arrowheads). ( $a$ and $b$ ) Bar, $250 \mathrm{~nm}$. (c) Freeze-fractured multilamellar particles from the LDL fraction of bile duct-ligated $\mathrm{Mdr}^{+/+}$mice. The particle displays the fracture characteristic of lipid bilayers. Bar, $100 \mathrm{~nm}$. (d) Cryotransmission electron microscopy of the LDL fraction of bile duct-ligated $M d r 2^{+/+}$mice. The picture displays a heterogenous liposome population, including oligolamellar vesicles (arrowheads). Bar, $250 \mathrm{~nm}$.

the canaliculus. This suggests that Mdr2 Pgp is not only present in the canalicular membrane but also in subapical vesicles.

\section{Discussion}

The data presented in this manuscript demonstrate that class III Pgp's play a key role in the generation of the abnormal cholestatic lipoprotein, LpX. Not only was LpX completely absent in bile duct-ligated mice that do not express Mdr2 Pgp, but in addition, the plasma concentration of LpX correlated very closely with the expression level of Mdr2 or MDR3 Pgp. This could be demonstrated by the use of a set of mice that express different levels of Mdr2 or MDR3 Pgp. MDR3 Pgp is the human homolog of the mouse Mdr2 Pgp and serves the same function: the translocation of phosphatidylcholine across the canalicular membrane of the hepatocyte. Smith et al. (17) showed that transgenic expression of MDR3 Pgp in Mdr2 ${ }^{-/-}$ mice restores biliary phospholipid secretion and also abrogates the development of liver disease in these animals.

The existence of $\mathrm{LpX}$ had never been shown in mice before and therefore we had to characterize the lipoprotein distribution under cholestatic conditions in these animals. According to several criteria, we found that $\mathrm{LpX}$ is indeed present in cholestatic murine plasma and actually represents the major lipoprotein under these conditions. Agarose electrophoresis, gradient ultracentrifugation, and gel filtration of cholestatic plasma demonstrated that murine $\mathrm{LpX}$ behaves very similarly as reported for other species $(3,4,21)$. Electron microscopy proved that murine $\mathrm{LpX}$ is a $40-100 \mathrm{~nm}$ liposomal particle. While the majority of phospholipid and cholesterol in bile duct-ligated $M d r 2^{+/+}$mice was present as LpX, virtually no lipid was detected at this density in $M d r 2^{-/-}$mice, demonstrating that these animals do not generate LpX. An important conclusion from our study is therefore that Mdr2 Pgp is essential for the formation of LpX. This is in line with the hypothesis $(3,5)$ that $\mathrm{LpX}$ is derived from biliary vesicles that in some way end up in the plasma.

The obvious question arises as to how these vesicles are formed and how they get into the plasma compartment. Comparison of the normal biliary phospholipid output with the rise in plasma phospholipid during the initial phase of cholestasis reveals that these are of comparable magnitude. Fig. 1 shows that plasma phospholipid increases linearly from 8-48 h of cholestasis with a rate of $\sim 400 \mu \mathrm{M} / \mathrm{h}$. Taking into account a 

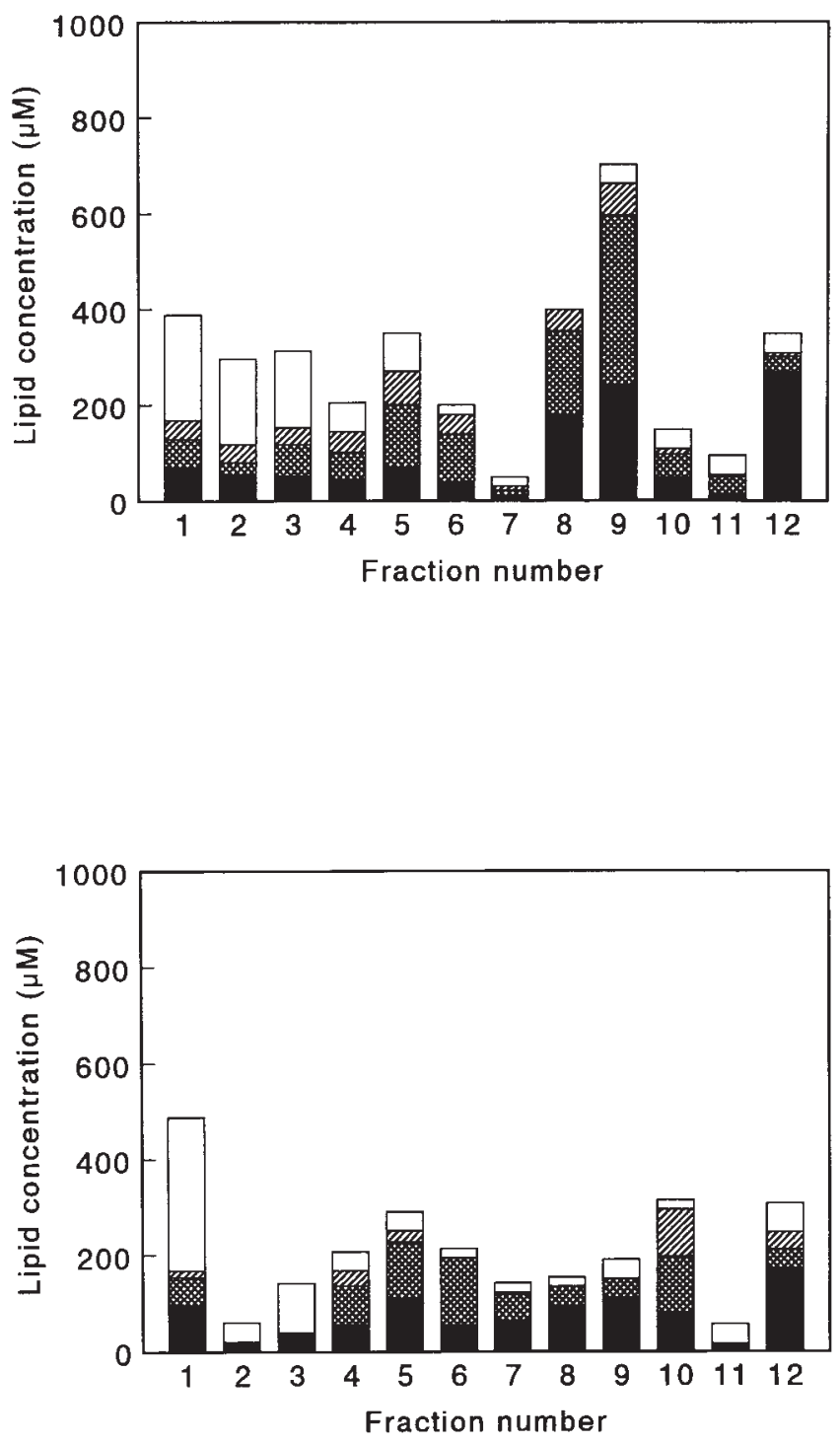

Figure 6. Density gradient ultracentrifugation of plasma from shamoperated and bile duct-ligated $M d r 2^{-1-}$ mice. $M d r 2^{-1-}$ mice were subjected to BDL or sham operation, and after $4 \mathrm{~d}$ plasma was sampled. Pooled plasma from four mice $(1 \mathrm{ml})$ was loaded onto a $\mathrm{KBr}$ density gradient, after which lipoproteins were separated by ultracentrifugation. Lipids were determined in the collected fractions $(1 \mathrm{ml})$. (Upper panel) Sham-operated mice; (lower panel) bile duct-ligated mice. Note that the scales of the ordinates in the two panels are different from those in Fig. 3. Solid bars, phospholipid; hatched bars, free cholesterol; double-hatched bars, esterified cholesterol; open bars, triglycerides.

plasma volume of $3 \mathrm{ml} / 100 \mathrm{~g}$, this would mean an increase of $20 \mathrm{nmol} / \mathrm{min} 100 \mathrm{~g}$. This figure represents an underestimation of the phospholipid output of the liver into the circulation because it ignores the (re)uptake of phospholipid by the liver and/or other tissues (see below). We have reported that normal, noncholestatic FVB mice have an endogenous biliary phospholipid secretion of $27 \mathrm{nmol} / \mathrm{min} / 100 \mathrm{~g}$. Thus, the sinusoidal lipid output during cholestasis is of comparable magnitude to the biliary output under normal circumstances. Whatever the mechanism for the entry of biliary ( $\mathrm{LpX})$ vesicles into the plasma, it must be very efficient since it causes a nearly quanti-

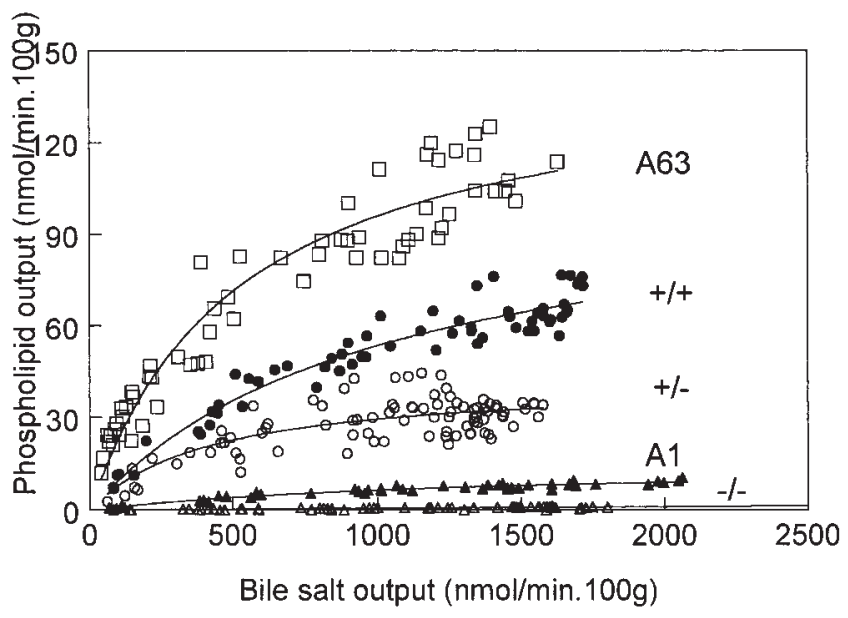

Figure 7. Biliary phospholipid secretion by transgenic mouse strains with different $M d r 2$ and $M D R 3$ expression. After cannulation, bile from animals of the indicated strains was diverted for $90 \mathrm{~min}$ to deplete the endogenous bile salt pool. Subsequently, tauroursodeoxycholate was infused during $150 \mathrm{~min}$ via the tail vein at stepwise increasing rates between 600 and $2400 \mathrm{nmol} / \mathrm{min} / 100 \mathrm{~g}$, and during this infusion bile was sampled. The samples were analyzed for their phospholipid content. The data represent values from individual bile samples from four animals. The A63 strain and the A1 strain are transgenes that express MDR3 Pgp at 200\% and 8\% of the level of Mdr2 Pgp in control mice, respectively, as determined by densitometric analysis of Western blots. The A1 mouse was bred against a $M d r 2^{-1-}$ background and, therefore, does not express Mdr2 Pgp. The A63 mouse was bred against a $M d r 2^{+/+}$background and, therefore, expresses endogenous Mdr2 Pgp as well as MDR3 Pgp. The $M d r 2^{+/-}$ and $M d r 2^{-1-}$ mice have $50 \%$ and $0 \% \mathrm{Mdr} 2 \mathrm{Pgp}$ expression, respectively.

tative shift of biliary lipid output from the canaliculus to the plasma compartment.

We have hypothesized that the combined action of Mdr2 Pgp and bile salt secretion leads to the formation of biliary vesicles directly at the canalicular membrane. This hypothesis is supported by a morphological study of Crawford et al. (16), who observed that biliary lipid secretion is associated with the presence of very characteristic adherent lipid vesicles on the outer leaflet of the canalicular membrane. It can be concluded from the present data that LpX has to be formed at the site where Mdr2/MDR3 Pgp is present.

One possible hypothesis is that biliary vesicles are still formed at the canalicular membrane and secreted into the canaliculus. These vesicles would then either have to be regurgitated into the hepatocyte and transcytosed to the sinusoidal pole of the cell, where they are released, or they would have to pass from the biliary compartment to the plasma through the paracellular route. The latter mechanism would require that tight junctions of the hepatocytes and/or of the bile duct epithelial cells are opened to such an extent that $70-\mathrm{nm}$ vesicles can quantitatively pass. This is rather unlikely because opening of the tight junctions to such an extent would certainly lead to a complete loss of cell polarity, which is not observed. During BDL, Mdr2 Pgp is still present in the canalicular region (Fig. 9). There is also little redistribution of other canalicular proteins to the sinusoidal membrane and no redistribution of sinusoidal membrane proteins to the canaliculus during BDL (24, 25). Our data and those from others (26) suggest that Pgp's un- 


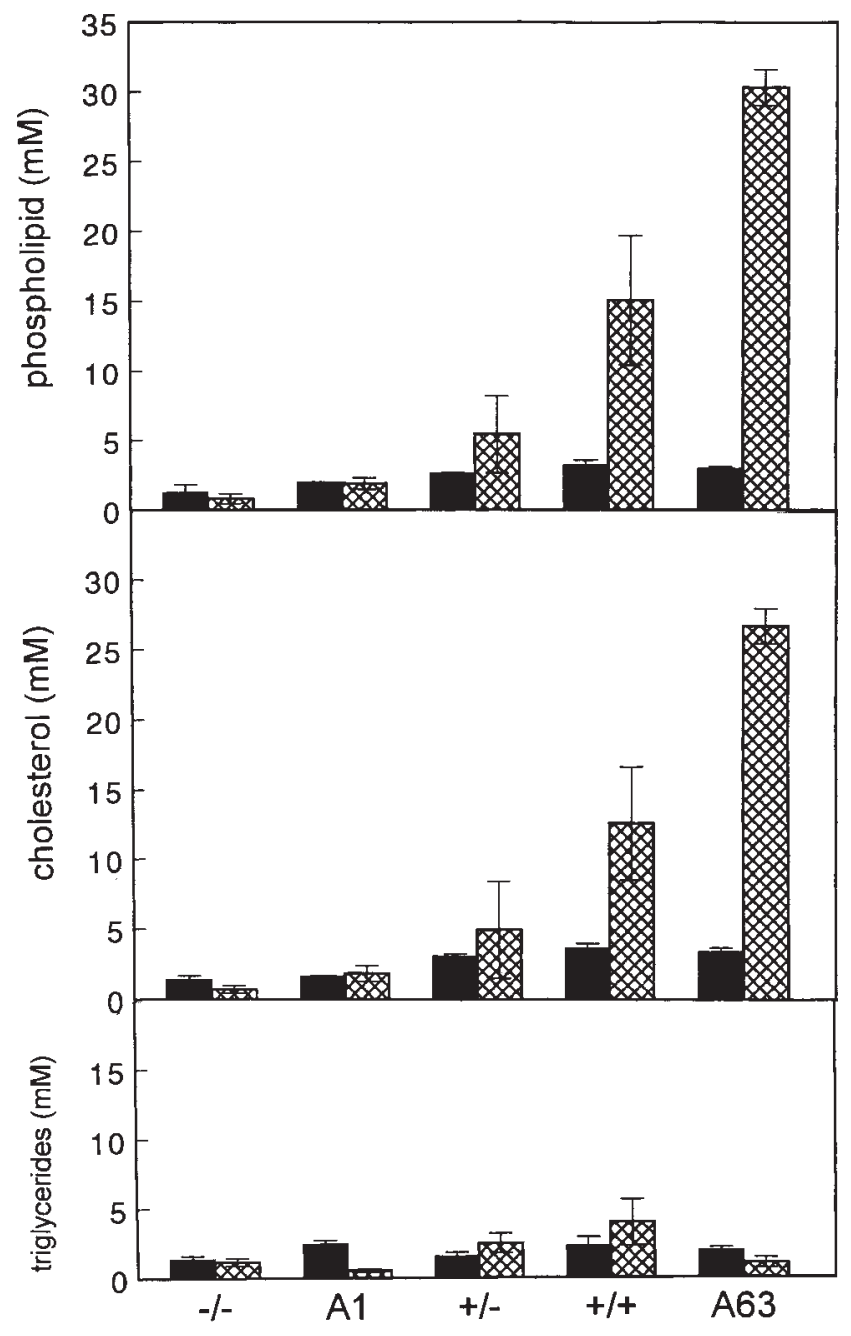

Figure 8. Plasma phospholipid, cholesterol, and triglyceride levels during BDL in mice with different $M d r 2$ or $M D R 3$ expression. Mice from the genotypes indicated in Fig. 7 were sham operated (solid bars) or subjected to BDL (cross-hatched bars) for $4 \mathrm{~d}$, after which plasma was sampled and analyzed for phospholipid (upper panel), total cholesterol (middle panel), or triglyceride (bottom panel). The data represent means \pm SD from three animals in each group.

dergo significant redistribution to a pericanalicular, vesicular compartment during cholestasis, but that they are not at all found in the sinusoidal membrane. As discussed above, Mdr2 Pgp-mediated lipid translocation seems to continue almost quantitatively during BDL. This observation, combined with the presence of the canalicular transporters in pericanalicular vesicles, suggests that the formation of LpX may actually predominantly take place in this subapical compartment. From this compartment, LpX may then be transcytosed to the sinusoidal membrane and released into the plasma. Clearly, this mechanism is hypothetical and needs to be tested. A report by Felker et al. (3) suggests, however, that this is a plausible hypothesis. In an electron microscopic study of livers from bile duct-ligated rats, they observed LpX-like vesicles in the canaliculus in the presence of intact tight junctions. In addition, the LpX-like vesicles were also observed within pericanalicular compartments.

In accordance with other reports, we observed two effects of cholestasis on the lipoprotein distribution; an increased lipid
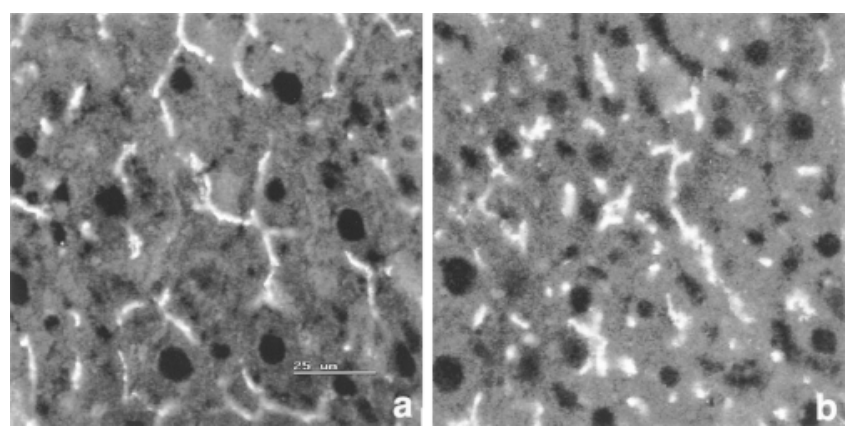

Figure 9. Immunofluorescence localization of Mdr2 Pgp in shamoperated and bile duct-ligated $M d r 2^{+/+}$mice. Livers from $M d r 2^{+/+}$ mice that were subjected to sham operation (left) or BDL (right) were stained with anti-REG3, an antibody that specifically reacts with Mdr2 Pgp and not with Mdr1 Pgp's or sister of Pgp. Antibodies were visualized with a FITC-conjugated second antibody and analyzed by confocal laser scanning microscopy.

content of the LDL fraction (i.e., the appearance of $\mathrm{LpX}$ ) and a decreased lipid content of the HDL fraction. The latter event was observed in $M d r 2^{-/-}, M d r 2^{+/+}$, and A63 mice. Apparently, the decrease in HDL is not related to the level of Mdr2 or MDR3 Pgp expression, i.e., the presence or absence of LpX. It must therefore represent an independent effect of cholestasis. Its cause is unknown but may involve an increased removal of HDL from the plasma or a decreased HDL synthesis. This phenomenon may also be related to the reported decrease in lecithin/cholesterol acetyltransferase levels in cholestatic plasma. Reduced esterification of cholesterol will impair the uptake of cholesterol by HDL from peripheral tissues (and possibly also from LpX). Total plasma cholesterol levels in $M d r 2^{+/+}$lagged during the first $8 \mathrm{~h}$ of cholestasis before they started to rise. The percentage of free cholesterol, however, started to rise immediately after BDL. This phenomenon might be explained by assuming that during the first $8 \mathrm{~h}$ of cholestasis, the fall in HDL cholesterol compensates for the rise in LpX cholesterol. This would mean that the fall in HDL cholesterol is a rapid event.

Remarkably, we observed that the plasma cholesterol and phospholipid concentrations during cholestasis are linearly related to the level of Mdr2/MDR3 Pgp expression, while this is not the case under noncholestatic conditions. After $2 \mathrm{~d}$ of cholestasis, steady-state concentrations of these lipids are reached (Fig. 1) and LpX is then the main lipoprotein. Plasma lipid concentrations will be determined by the input into and the removal of lipid from the plasma compartment. Our data demonstrate that during cholestasis the input of cholesterol and phospholipid into plasma via Pgp-mediated LpX formation governs the plasma level of LpX. From this it can be concluded that the removal of LpX must concern a deep compartment with low affinity for $\mathrm{LpX}$, the activity of which increases linearly with the plasma LpX concentration. Walli and Seidel (27) studied the uptake of LpX by different cell types and suggested that uptake is mainly mediated by cells of the reticuloendothelial system. This would involve fluid phase endocytosis, which would explain the nonsaturability of the removal pathway. These observations are in line with the fact that patients with chronic cholestasis (PBC patients) accumulate cholesterol in xanthomata (28).

The almost twofold increased expression of MDR3 Pgp in A63 mice compared with Mdr2 Pgp expression in $M d r 2^{+/+}$ 
mice led to a similarly increased cholesterol and phospholipid concentration in plasma during cholestasis. Because there is no enterohepatic circulation of phospholipid and cholesterol during cholestasis, and the lipid content of the food did not change either, it can be concluded that the cholesterol as well as phospholipid synthesis are increased in A63 mice compared with $M d r 2^{+/+}$mice. This would mean that, at least under cholestatic conditions, the synthesis of both cholesterol and phospholipid is regulated by Mdr2/MDR3 Pgp. Indeed, by pulling cholesterol and phospholipid out of the liver in the form of LpX, Pgp activity could lead to an emptying of the hepatic cholesterol and phospholipid pool, thereby increasing synthesis in a "pull" mechanism. The hepatocyte does not take up LpX to a significant extent (27), and, in line with this, it has been shown that $\mathrm{LpX}$ is unable to inhibit cholesterol synthesis in HepG2 cells (29) and perfused livers (30). This lack of feedback inhibition from the plasma compartment would explain the paradoxical observation made in several studies $(31,32)$ that cholesterol synthesis is increased during cholestasis while this is a situation of hypercholesterolemia. Similarly, it has been reported that phospholipid synthesis is increased during cholestasis (33).

In conclusion, we show that the appearance of LpX in plasma during cholestasis depends on the activity of class III Pgp's, presumably by the continued formation of biliary vesicles at the canalicular membrane and in subapical vesicles. We assume that these LpX particles are transcytosed to the sinuoidal membrane and released into the blood. This mechanism has profound effects on the lipid homeostasis during cholestasis.

\section{Acknowledgments}

We thank Prof. Piet Borst and Prof. Don Ostrow for critically reading the manuscript.

This work was supported by the Dutch Organization for Scientific Research (NWO), project \#902-23-097.

\section{References}

1. Seidel, D., P. Alaupovic, and R.H. Furman. 1969. A lipoprotein characterizing obstructive jaundice. I. Method for quantitative separation and identification of lipoproteins in jaundiced subjects. J. Clin. Invest. 48:1211-1223.

2. Kunkel, H.G., and E.H. Ahrens. 1949. The relationship between serum lipids and the electrophoretic pattern, with particular reference to patients with primary biliary cirrhosis. J. Clin. Invest. 28:1575-1579.

3. Felker, T.E., R.L. Hamilton, and R.J. Havel. 1978. Secretion of lipoprotein-X by perfused livers of rats with cholestasis. Proc. Natl. Acad. Sci. USA. 75: 3459-3463.

4. O, K., and J. Frohlich. 1995. Role of lecithin:cholesterol acyltransferase and apolipoprotein A-1 in cholesterol esterification in lipoprotein $\mathrm{X}$ in vitro. $J$. Lipid Res. 36:2344-2354.

5. Manzato, E., R. Fellin, G. Baggio, S. Walch, W. Neubeck, and D. Seidel. 1976. Formation of LpX. Its relationship to bile compounds. J. Clin. Invest. 57: 1248-1260.

6. Hamilton, R.L., R.J. Havel, J.P. Kane, A.E. Blaurock, and T. Sata. 1971. Cholestasis: lamellar structure of the abnormal human serum lipoprotein. Science. 172:475-478.

7. Laggner, P., O. Glatter, K. Muller, O. Kratky, G. Kostner, and A. Holasek. 1977. The lipid bilayer structure of the abnormal human plasma lipoprotein X. An X-ray small-angle-scattering study. Eur. J. Biochem. 77:165-171.

8. Picard, J., D. Veissiere, F. Voyer, and G. Bereziat. 1971. Composition en acides gras des phospholipides dans les lipoprotéines sériques anormales de la cholostase. Clin. Chim. Acta. 36:247-250.

9. Sabesin, S.M. 1982. Cholestatic lipoproteins-their pathogenesis and sig- nificance. Gastroenterology. 83:704-709.

10. Guerin, M., P.J. Dolphin, and M.J. Chapman. 1993. Familial lecithin: cholesterol acyltransferase deficiency: further resolution of lipoprotein particle heterogeneity in the low density interval. Atherosclerosis. 104:195-212.

11. Tashiro, T., Y. Mashima, H. Yamamori, K. Horibe, M. Nishizawa, M. Sanada, and K. Okui. 1991. Increased lipoprotein X causes hyperlipidemia during intravenous administration of $10 \%$ fat emulsion in man. J. Parenter. Enter. Nutr. 15:546-550.

12. Smit, J.J.M., A.H. Schinkel, R.P.J. Oude Elferink, A.K. Groen, E. Wagenaar, L. Van Deemter, C.A.A.M. Mol, R. Ottenhoff, N.M.T. Van der Lugt, M.A. van Roon, et al. 1993. Homozygous disruption of the murine mdr2 P-glycoprotein gene leads to a complete absence of phospholipid from bile and to liver disease. Cell. 75:451-462.

13. Oude Elferink, R.P.J., G.N.J. Tytgat, and A.K. Groen. 1997. The role of mdr2 P-glycoprotein in hepatobiliary lipid transport. FASEB (Fed. Am. Soc. Exp. Biol.) J. 11:19-28.

14. Oude Elferink, R.P.J., R. Ottenhoff, M. van Wijland, J.J.M. Smit, A.H Schinkel, and A.K. Groen. 1995. Regulation of biliary lipid secretion by mdr2 P-glycoprotein in the mouse. J. Clin. Invest. 95:31-38.

15. Crawford, J.M., G. Möckel, A.R. Crawford, S.J. Hagen, V.C. Hatch, S. Barnes, J.J. Godleski, and M.C. Carey. 1995. Imaging biliary lipid secretion in the rat: ultrastructural evidence for vesiculation of the hepatocyte canalicular membrane. J. Lipid Res. 36:2147-2163.

16. Crawford, A.R., A.J. Smith, V.C. Hatch, R.P.J. Oude Elferink, P. Borst, and J.M. Crawford. 1997. Hepatic secretion of phospholipid vesicles in the mouse critically depends on mdr2 or MDR3 P-glycoprotein expression. Visualization by electron microscopy. J. Clin. Invest. 100:2562-2567.

17. Smith, A.J., J.M.L. de Vree, R. Ottenhoff, R.P.J. Oude Elferink, A.H. Schinkel, and P. Borst. 1998. Hepatocyte-specific expression of the human MDR3 P-glycoprotein gene restores the biliary phosphatidylcholine excretion absent in Mdr2(-/-) mice. Hepatology. 28:530-536.

18. Chapman, M.J., S. Goldstein, D. Lagrange, and P.M. Laplaud. 1981. A density gradient ultracentrifugal procedure for the isolation of the major lipoprotein classes from human serum. J. Lipid Res. 22:339-358.

19. Huang, H.S., J.C.W. Kuan, and G.G. Guibault. 1975. Fluorimetric enzymatic determination of total cholesterol in serum. Clin. Chem. 21:1605-1608.

20. Voshol, P.J., R. Havinga, H. Wolters, R. Ottenhoff, H.M.G. Princen, R.P.J. Oude Elferink, A.K. Groen, and F. Kuipers. 1998. Reduced plasma cholesterol and increased fecal sterol loss in multidrug resistance gene $2 \mathrm{P}$-glycoprotein deficient mice. Gastroenterology. 114:1024-1034.

21. Chisholm, J.W., and P.J. Dolphin. 1996. Abnormal lipoproteins in the ANIT-treated rat: a transient and reversible animal model of intrahepatic cholestasis. J. Lipid Res. 37:1086-1098.

22. Juranka, P.F., R.L. Zastawny, and V. Ling. 1989. P-glycoprotein: multidrug resistance and a superfamily of membrane-associated transport proteins. FASEB (Fed. Am. Soc. Exp. Biol.) J. 3:2583-2592.

23. Smit, J.M.M., A.H. Schinkel, C.A.A.M. Mol, D. Majoor, W.J. Mooi, A.P.M. Jongsma, C.R. Lincke, and P. Borst. 1994. Tissue distribution of the human MDR3 P-glycoprotein. Lab. Invest. 71:638-649.

24. Barr, V.A., and A.L. Hubbard. 1993. Newly synthesized hepatocyte plasma membrane proteins are transported in transcytotic vesicles in the bile duct ligated rat. Gastroenterology. 105:554-571.

25. Stieger, B., P.J. Meier, and L. Landmann. 1994. Effect of obstructive cholestasis on membrane traffic and domain-specific expression of plasma membrane proteins in rat liver parenchymal cells. Hepatology. 20:201-212.

26. Accatino, L., M. Pizarro, N. Solis, C.S. Koenig, V. Vollrath, and J. Chianale. 1996. Modulation of hepatic content and biliary excretion of P-glycoproteins in hepatocellular and obstructive cholestasis in the rat. J. Hepatol. 25:349-361.

27. Walli, A.K., and D. Seidel. 1984. Role of lipoprotein X in the pathogenesis of cholestatic hypercholesterolemia. J. Clin. Invest. 74:867-879.

28. Ahrens, E.H., and H.G. Kunkel. 1949. The relationship between serum lipids and skin xanthomata in eighteen patients with primary biliary cirrhosis. $J$. Clin. Invest. 28:1565-1574.

29. Edwards, C.M., M.P. Otal, and P.W. Stacpoole. 1993. Lipoprotein X fails to inhibit hydroxymethylglutaryl coenzyme A reductase in HepG2 cells. Metabolism. 42:807-813.

30. Liersch, M., G. Baggio, C.C. Heuck, and D. Seidel. 1977. Effect of lipoprotein X on hepatic cholesterol synthesis. Atherosclerosis. 26:505-514.

31. Kattermann, R., and W. Creutzfeldt. 1970. The effect of experimental cholestasis on the negative feedback regulation of cholesterol synthesis in rat liver. Scand. J. Gastroenterol. 5:337-342.

32. Harry, D.S., M. Dini, and N. McIntyre. 1973. Effect of cholesterol feeding and biliary obstruction on hepatic cholesterol biosynthesis in the rat. Biochim. Biophys. Acta. 296:209-220.

33. McIntyre, N., D.S. Harry, and A.J.G. Pearson. 1975. The hypercholesterolemia of obstructive jaundice. Gut. 16:379-391. 